\title{
System identification applied to a single area electric power system under frequency response
}

\author{
José Angel Barrios ${ }^{1}$, F. Sanchez ${ }^{2}$, Francisco Gonzalez-Longatt ${ }^{3}$, Gianfranco Claudio ${ }^{4}$ \\ ${ }^{1,2,4}$ Centre for Renewable Energy Systems Technology, Loughborough University, Loughborough, United Kingdom \\ ${ }^{1}$ Posgrado en Ingeniería Eléctrica, Facultad de Ingeniería Mecánica y Eléctrica, Universidad Autónoma de Nuevo León, \\ San Nicolás de los Garza, N.L., México \\ ${ }^{1}$ Universidad Politécnica de García, García, N.L., México \\ ${ }^{3}$ Department of Electrical engineering, Information Technology and Cybernetics, Campus Porsgrunn, \\ University of South-Eastern Norway, Notodden, Norway
}

\begin{tabular}{l}
\hline \hline Article Info \\
\hline Article history: \\
Received Oct 26, 2020 \\
Revised Feb 12, 2021 \\
Accepted Feb 23, 2021 \\
\hline
\end{tabular}

\section{Keywords:}

Frequency response Parameter estimation Power systems System identification Systems modelling

\begin{abstract}
This research paper proposes a methodology to apply identification methods to find a simplified model of three different governors in a single area electric power system (SAEPS). A SAEPS with different governors-turbine is presented: a hydraulic turbine, a steam turbine and a steam reheat turbine. In this same investigation, an analytic reduction has been performed, a fifth order system was found analytically, thus a transfer function equivalent to the three different governor-turbine elements was obtained, this equivalent transfer function models the complete behavior of the three devices. Two systems identification (SI) algorithms have been proposed to apply them to this generic subspace state-space (N4SID) and generalized poisson moment functionals (GPMF) electrical system, these presented similar results. The results of the performance and simulation analysis exhibit that using the SI technique, fifth, fourth and third-order systems were obtained that graphically show a very small estimation error compared to the original signal, this fact could be check simulating the simplified models using the same input-output data. The results are presented in a table that shows a comparison of the model respond the fifth, fourth, third and second-order systems.
\end{abstract}

This is an open access article under the CC BY-SA license.

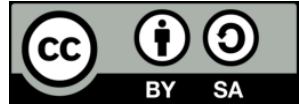

\section{Corresponding Author:}

José Angel Barrios

Posgrado en Ingeniería Eléctrica, Facultad de Ingeniería Mecánica y Eléctrica

Universidad Autónoma de Nuevo León,

San Nicolás de los Garza, N.L., México

Email: joseangel_barrios@yahoo.com.mx

\section{INTRODUCTION}

The electrical industry is constantly changing and evolves technologically every day, trying to find and improve the efficiency and reliability with which electrical energy is produced. So many modelling techniques and simulation tools have been used to implement the processes in the production of electric energy and make this faster and more precise. The main focus of the dynamics of the turbine governor is to present the initial response produced in the seconds just after a disturbance of this network [1]. In many papers different techniques have been applied to model and simplify the turbine governor, in several cases, they are intelligent controllers, adaptive controllers and proportional-integral-derivative (PID) controllers [2]-[4]. Although traditional PID controllers do not respond efficiently when there are nonlinearities in complex processes. A simplified model of an area with different generation is of great importance when conducting 
studies for frequency control and stability of the electrical system. Thus, it is possible to understand that, the frequency response is a primary aspect of the performance of the power system (PS) [5]-[7].

Obtaining a simplified model of the turbine governor is critical when PS stability studies are conducted and used primarily for frequency stability, voltage stability, transient angles, small-signal stability and control, several authors have generally conducted research and studies to model the turbine governor [8]-[12]. This research proposes a structure to apply systems identification (SI) methods to find a simplified model of three governors in a single area electric power system (SAEPS). This paper presents a SAEPS with different types of electrical generation that are: hydraulic turbine, steam turbine, and a steam reheat turbine. To do this, it will be necessary to perform an analytic reduction and find the minimum order of the system, this equivalent transfer function will model the complete behaviour of the three devices in parallel. Two SI algorithms that will be used to the generic electrical system have been proposed, these algorithms are called generalized poisson moment functionals (GPMF) and numeric algorithms for the subspace state-space (SS) SI (NS4SID), which will be explained later.

\section{METHOD}

The SI process is a method, art and science of structure mathematical models of dynamic systems taking the measures of the systems output and input signals [13]. The following describes the methodology needed to find a simplified model of a single area power control, where there may be $\mathrm{N}$ units with different kinds of governors. The process of SI, involves the following steps corresponding for the development of the proposed methodology are described: i) Step 1: The input-output variables of the set of $\mathrm{N}$ governors of an electric PS are selected, this will provide the corresponding input-output data set, some data processing is performed if necessary; ii) Step 2: To estimate, the SI takes the input and output data and applies the identification algorithm to find the system parameters that show a minimum error; iii) Step 3: To analyze the predicted models, the best way is to simulate in dedicated software, for this case Matlab Simulink will be used, applying the same input that was used to the original model and thus output is obtained; and iv) Step 4: For the validation of the parameters found by the identification algorithm, it is necessary to compare the output obtained from step 4 , then calculate the estimation error to see the performance.

\subsection{Simplified modelling}

The procedure for modeling a system requires, take the measurements of output and input variables from the primal SAEPS in frequency or time domain and the model structure need to be selected: transfer function (TF) or SS. The SI uses the output and input measurement of the variables of a system to estimate the values of the adaptable parameters in a specify model frame. The measured data must adequately reflect the behavior of each system, since the obtaining of its parameters depends on this, in most cases, it depends on the amount of data. Therefore, it is requiered to apply in the frame of the candidate model an estimation methodology to obtein the value of the adjustable parameters, the next step would be to evaluate the estimated model by validation.

As referred to above, the motivation of this document is to discover an equivalent model of $n$ SAEPS that can substitute the different kinds of a governor that the area contains. To demonstrate this technique, a SAEPS with three kinds of the governor are proposed, which are: the steam turbine, the Steam reheat turbine and the hydraulic turbine, Figure 1.

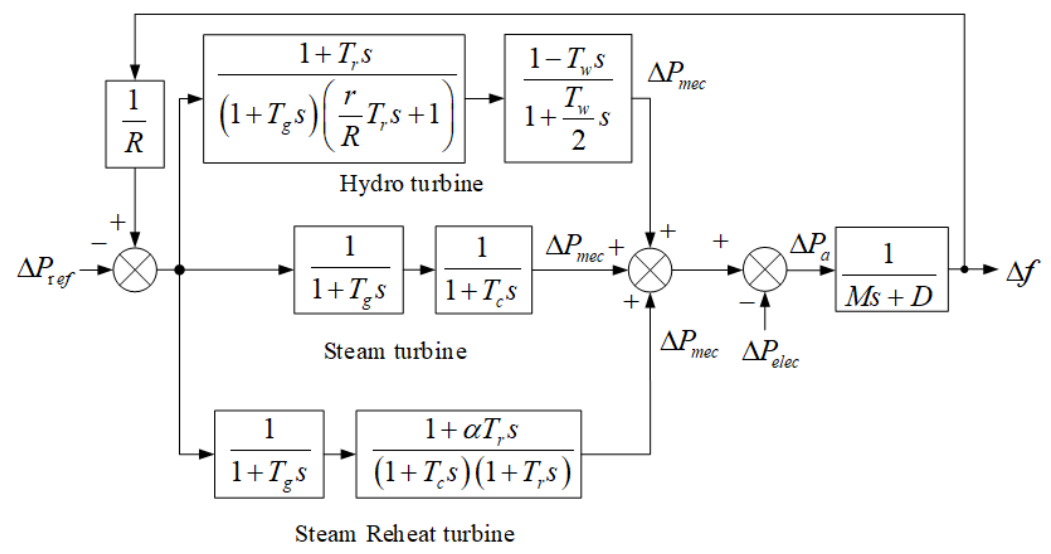

Figure 1.. SAEPS with a different generation source 


\subsection{Single area model description}

Normally, an isolated electrical area, where a generating unit or a group of generating units is placed nearby to distribute electricity in the same area is called a SAEPS. There is no other generator unit that is far away, only the generating units present in that area are responsible for maintaining the desired frequency in normal and abnormal conditions [14]. The general generator-load dynamic relation between the frequency deviation $(\Delta \mathrm{f})$ and the incremental mismatch power $(\triangle P m-\Delta P L)$ is denoted as (1).

$$
\Delta P_{m}(t)-\Delta P_{L}(t)=2 H \frac{d \Delta f(t)}{d t}+D \Delta f(t)
$$

Where $\Delta \mathrm{Pm}$ the mechanical power change, $\Delta \mathrm{PL}$ the load change, $\Delta \mathrm{f}$ is the frequency deviation, $\mathrm{D}$ is the load damping coefficient and $\mathrm{M}$ the inertia constant. Thus, the damping coefficient is in general defined as a per cent change in load for a one percent change in frequency. Hence, a value of one and a half for D imply that a one percent change in frequency give rise to a one and a half percent change in load. Applying the Laplace transformation, it is described as (2).

$$
\Delta P_{m}(s)-\Delta P_{L}(s)=2 H s \Delta f(s)+D \Delta f(s)
$$

In general, low order models have been proposed for the representation of the dynamics of turbines and generators ( $\mathrm{Gt}$ and $\mathrm{Gg}$ ) for use in the frequency analysis of the PS and the control design. The slow and fast dynamics of the boiler system and the generator system are generally not included in the models used. The block diagram scheme of the speed controller and the turbine for the steam and hydraulic regulator units appropiate for the load frequency control analysis, is shows in Figure 2. Where R shows the regulation of the speed thanks to the action of the regulatoris and is the speed velocity characteristic [14], [15]. The TFs that are shown next to the governor-turbine schemes in Figure 2, are the equivalences and define the behaviour of these elements

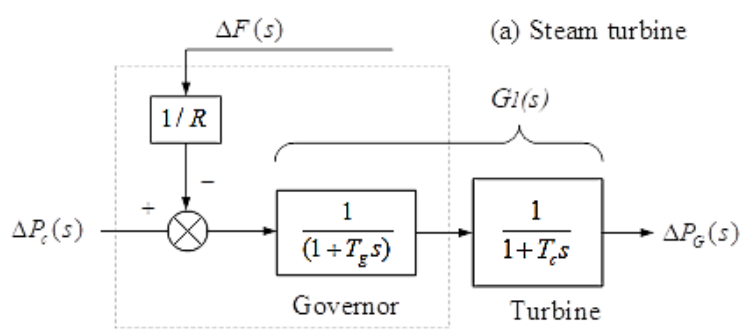

(a)

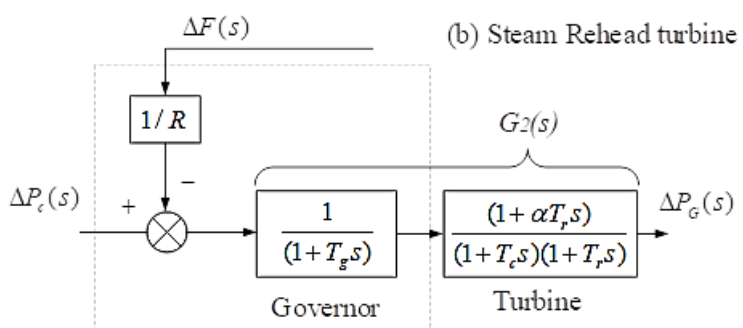

(b)

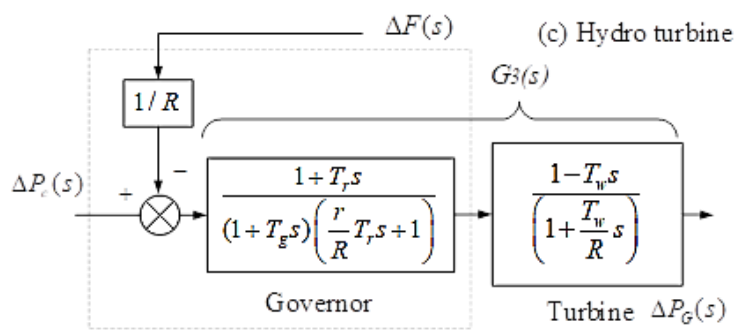

(c)

Figure 2. Different governors in a SAEPS: (a) steam turbine, (b) steam rehead turbine, and (c) hydro turbine

\subsection{Analytical equivalent}

In the (3) and (4), it can be observed that the three types of the governor can be reduced by mathematical operations, this is possible and relatively simple because, we are working with a singular area PS, this would not be so easy to be an $n$ area PS. This is one of the reasons why a parameter estimation algorithm is proposed.

$$
G_{o v}=G_{1}(s)+G_{2}(s)+G_{3}(s)
$$


substituting:

$$
G_{O V}=\frac{1}{\left(T_{c} c^{S+1)\left(T_{g} S+1\right)}\right.}+\frac{T_{r} a s+1}{\left(T_{c} s+1\right)\left(T_{g} S+1\right)\left(T_{r} S+1\right)}-\frac{\left(T_{r} S+1\right)\left(T_{w} S-1\right)}{\left(T_{g} S+1\right)\left(\frac{T_{w} S}{2}\right)\left(\frac{T_{r} r s}{R}+1\right)}
$$

The analytical result of the reduction is shown in (5), as can be seen, all the variables involved in the three governors were used, so that it results in a fifth-order TF.

$$
G_{o v}=\frac{\left(\alpha_{4} s^{4}+\alpha_{3} s^{3}+\alpha_{2} s^{2}+\alpha_{1} s+\alpha_{0} R\right)}{\left(\beta_{5} s^{5}+\beta_{4} s^{4}+\beta_{3} s^{3}+\beta_{2} s^{2}+\beta_{1} s+\beta_{0} R\right)}
$$

where:

$$
\begin{aligned}
\alpha_{4}= & -2 R T_{c} T_{r}{ }^{2} T_{w} \\
\alpha_{3}= & 2 R T_{c} T_{r}{ }^{2}-2 R T_{r}{ }^{2} T_{w}+T_{r}{ }^{2} T_{w} r+T_{r}{ }^{2} T_{w} a r-4 R T_{c} T_{r} T_{w} \\
\alpha_{2}= & 2 R T_{r}{ }^{2}+2 T_{r}{ }^{2} r+4 R T_{c} T_{r}-2 R T_{c} T_{w}-3 R T_{r} T_{w}+2 T_{r} T_{w} r+2 T_{r}{ }^{2} a r+R T_{r} T_{w} a \\
\alpha_{1}= & 2 R T_{c}+6 R T_{r}+4 T_{r} r+2 R T_{r} a \\
\alpha_{0}= & 6 \\
\beta_{5}= & T_{c} T_{g} T_{r}{ }^{2} T_{w} r \\
\beta_{4}= & 2 T_{c} T_{g} T_{r}{ }^{2} r+T_{c} T_{r}{ }^{2} T_{w} r+T_{g} T_{r}{ }^{2} T_{w} r+R T_{c} T_{g} T_{r} T_{w}+T_{c} T_{g} T_{r} T_{w} r \\
\beta_{3}= & 2 T_{c} T_{r}{ }^{2} r+2 T_{g} T_{r}{ }^{2} r+T_{r}{ }^{2} T_{w} r+2 R T_{c} T_{g} T_{r}+R T_{c} T_{g} T_{w}+R T_{c} T_{r} T_{w}+R T_{g} T_{r} T_{w}+2 T_{c} T_{g} T_{r} r+ \\
& T_{c} T_{r} T_{w} r+T_{g} T_{r} T_{w} r \\
\beta_{2}= & 2 T_{r}{ }^{2} r+2 R T_{c} T_{g}+2 R T_{c} T_{r}+2 R T_{g} T_{r}+R T_{c} T_{w}+R T_{g} T_{w}+R T_{r} T_{w}+2 T_{c} T_{r} r+2 T_{g} T_{r} r+ \\
& T_{r} T_{w} r \\
\beta_{1}= & 2 R T_{c}+2 R T_{g}+2 R T_{r}+R T_{w}+2 T_{r} r \\
\beta_{0}= & 2
\end{aligned}
$$

Furthermore, the model can be reduced by replacing the values of each variable in the TFs of each type of governor, the Table 1 shows the parameter and the corresponding values. The values are substituted in (3) TF and, therefore, it is possible to obtain a reduced equivalent analytical model, in (6) presenting the necessary operation.

$$
G(s)=\frac{1}{\left(\frac{s}{2}+1\right)\left(\frac{s}{10}+1\right)}+\frac{7 s+1}{\left(\frac{s}{2}+1\right)\left(\frac{s}{10}+1\right)\left(\frac{266 s}{5}+1\right)}+\frac{\frac{21 s}{10}+1}{\left(\frac{s}{2}+1\right)\left(\frac{s}{10}+1\right)(7 s+1)}
$$

Must perform mathematical operations to reduce (6), so the result is a simplified expression which is seen in (7). Only a fourth-order TF is used to represent the complete system.

$$
G_{O V_{2}}=\frac{53312 s^{2}+12950 s+300}{1862 s^{4}+22645 s^{3}+40857 s^{2}+6080 s+100}
$$

The data used as input is the $\Delta f$ and output the mechanical power $P m$, are used in the identification algorithm to calculate the parameters for the simplified model of the three areas, the system order was determined by analytical mathematical reduction. The SI need it that the data identify the significant dynamics of the system [16], this can be achieved with a large amount of data, in this document, tests are made with different data groups.

Table 1. Parameter values for SAEPS

\begin{tabular}{lccccccc}
\hline Parameters & $\mathrm{Tg}$ & $\mathrm{Tc}$ & $\mathrm{Tr}$ & $\alpha$ & $\mathrm{Tw}$ & $\mathrm{R}$ & $\mathrm{r}$ \\
\hline Value & 0.1 & 0.5 & 7 & 2.1 & 3 & 0.05 & 0.38 \\
\hline
\end{tabular}

\section{STRUCTURE OF THE SYSTEM IDENTIFICATION MODEL}

A model structure establishes a mathematical association of the input and output variables that have unknown parameters [17]. In SI, the order of the system is known in many cases. The order is the only structural parameter, in a single input and single output system, on the other hand in multivariate systems, there can be different structural parameters [18]. These model structures can be the TFs with adjustable zeros and poles, the SS equations with unspecified system matrices and the non-linear parametrized functions. The 
process of identifying the system requires put forward a model structure and put on the estimation methods to define the numerical values of the parameters of the model.

To choose the model structure is viable to use one of the next approaches: The model must be able to use the measured data and be as simple as possible; in vectors, it is most appropriate, several mathematical structures are tested in the algorithm. This kind of modelling approach it is known black-box modelling. A determined structure is necessary for the model, but it does not know the numerical values of its parameters. It is also possible to illustrate the framework of the model in the form of a group of equations or SS system and to estimate the values of the parameters from a set of data. Thereby the focusing is also called gray box modeling. The following identification methods for parameter estimation have been used in this document.

\subsection{Generalised poisson moment functionals (GPMF)}

Currently there is an algorithm to estimate parameters that use a generalized PMF approach. This algorithm increases a vector of parameters by the size of the system order $n$ terms related to the preliminary conditions. To estimate both terms: parameters and states, the observable phase variable form is used to represent the SS of a system. One of the advantages of this way of representing the observable phase variable is that the details that relate to the initial conditions in the parameter vector are the so-called initial states. Consequently, these states are estimated together with the parameters that the system has. Thus, each state vector at each instant of time afterwards is estimated at the same time as the parameters by recursively applying the initial states that were estimated [19]-[21].

\subsection{Numeric algorithms for subspace state-space system identification (NS4SID)}

The NS4SID formulated by Van Overschee and De Moor, perform calculations of parameterization of the model, resolving for the matrices $\mathrm{A}, \mathrm{B}$, and $\mathrm{C}$. The algorithm is noniterative and does not be conditional on a priori parameterization. An advantage of this method is that avoids problems such as local minima, initial condition bias and always find a convergent system. The SI is funded on singular value decomposition and QR which guarantee that the estimated linear time-invariant model is stable. The system order is the only information required for the identification process [22]-[24].

\subsection{Model parameters estimation}

The SI make a stimate of model parameters by minimizing the error among the model output and the measured response. Thus, the output $y_{\text {model }}$ of the linear model is represented by:

$$
y_{\text {model }}(t)=T_{f} u(t)
$$

where $T_{f}$ is the trasnsfer function. Thereby to establish the $T_{f}$, the algoritm minimizes the difference between the measured output $y_{\text {meas }}(t)$ and the model output $y_{\text {model }}(t)$. A weighted norm of the error $e(t)$, is the minimization criterion, where:

$$
e(t)=y_{\text {meas }}(t)-y_{\text {model }}(t)
$$

$y_{\text {mod el }}(t)$ is one of the subsequent: Simulated response (predicted response of the model for a given input $u(t), T_{f} u(t)$ of the model for a given input $u(t)$ and past measurements of output $\left.y_{\text {meas }}(t-1), y_{\text {meas }}(t-2), \ldots\right)$. Therefore, the error $e(t)$ is called prediction error or simulation error. The estimation algorithm fiting the parameters in the model structure $T_{f}$ to achieve that the norm of this error is as small as achievable [25].

\section{SIMULATION STUDIES AND RESULTS}

This section shows the simulations and the results, the following case are proposed. Figure 3shows the input and output of the three-unit model; the sample time is $0.1 \mathrm{~ms}$. The $\Delta \mathrm{f}$ is used as input because in this variable it is appropriate due to its nature sensitive to changes by power, and disturbances, the sum of the mechanical powers Pm was used as an output, because it represents the response of each of the governors. These inputs and outputs are shown for the experiment. An experiment using the algorithms N4SID and GPMF, expected to verify the system order that produces the smallest approach error. The experiments characteristics are defined in Table 2. Where $\Delta P_{\text {elec }}$ load power disturbance and $\Delta P_{\text {ref }}$ is a reference load power. The graphical results for each case of the experiment are shown in Figures 4 to 7 . Each of these figures is a case where it is possible to observe measured and simulated model output and measured minus simulated output. 


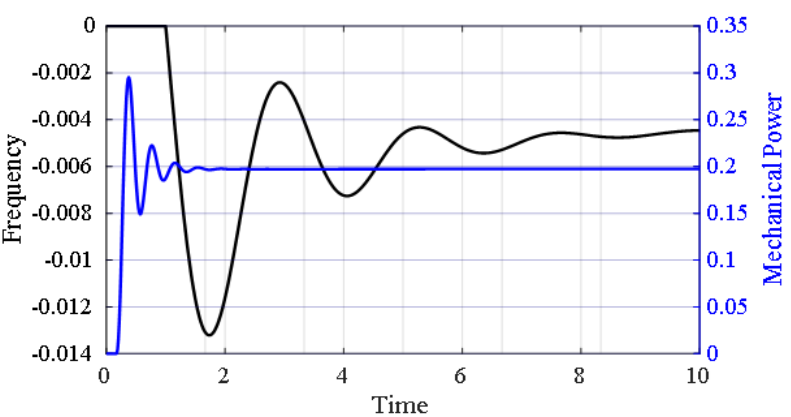

Figure 3. Frequency and mechanical power

Table 2. Summary of experiment features

\begin{tabular}{llll}
\hline & Experiment & & Experiment \\
\hline Simulation time & $60 \mathrm{~s}$ & Time format & Continuous time \\
$\Delta \mathrm{P}_{\text {elec }}$ & 0.2 & Initial condition Algorithm & Zero \\
$\Delta \mathrm{P}_{\text {ref }}$ & 0 & Initial Method: & N4SID, GPMF \\
Estimation data & Time - domain & Data & 600001 \\
Staring time & $0 \mathrm{~s}$ & First Case: & Fifth order \\
Sample time & 0.0001 & Second Case & Fourth order \\
Number of polos & $5,4,3,2$ & Third Case & Third order \\
Number of Zeros & $4,3,2,1$ & Fourth Case & Second order \\
\hline
\end{tabular}

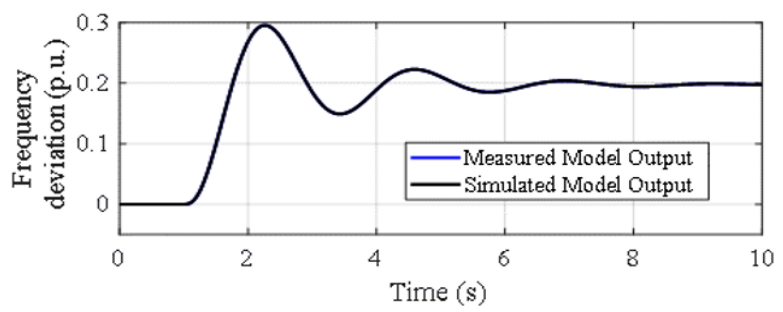

(a)

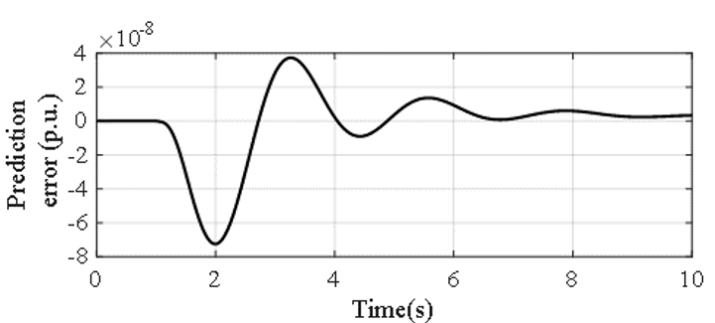

(b)

Figure 4. Experiment first case: (a) measured and simulated model output and (b) measured minus simulated output

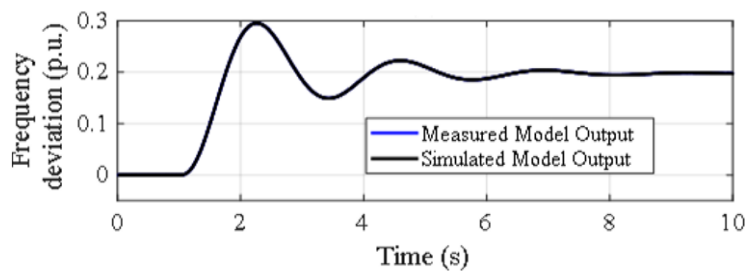

(a)

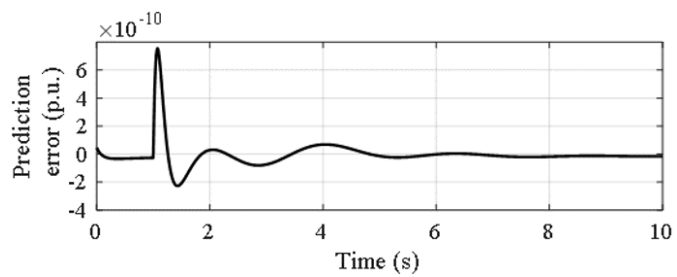

(b)

Figure 5. Experiment second case: (a) measured and simulated model output and (b) measured minus simulated output

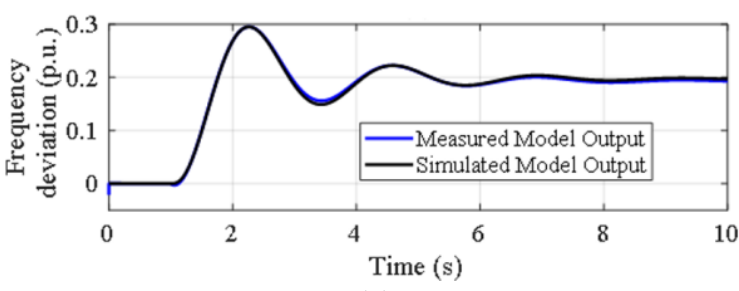

(a)

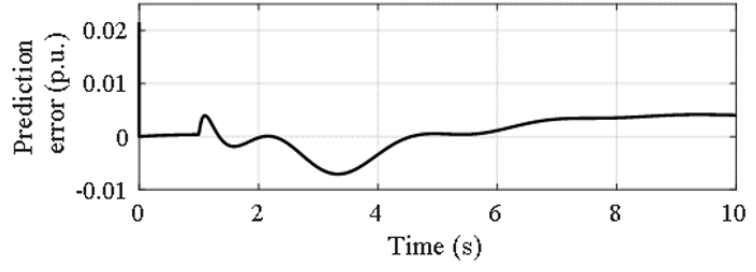

(b)

Figure 6. Experiment third case: (a) measured and simulated model output and (b) measured minus simulated output 


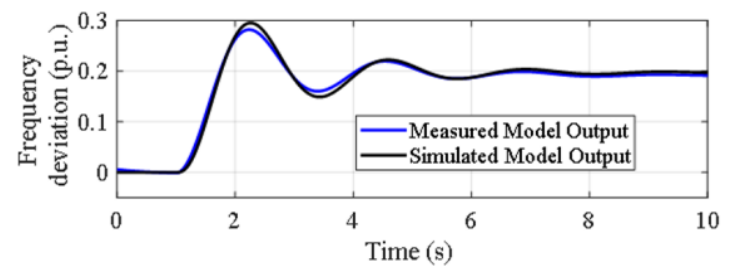

(a)

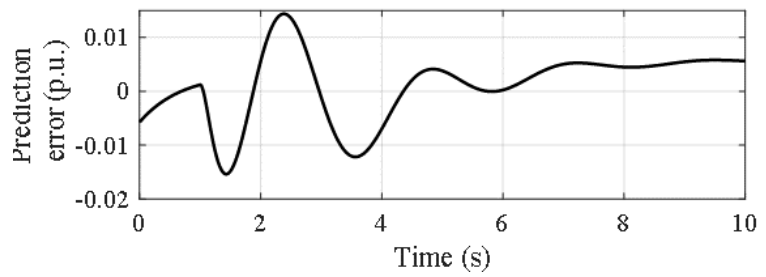

(b)

Figure 7. Experiment fourth case; (a) measured and simulated model output and (b) measured minus simulated output

\subsection{Presentation of result}

A system TF with a different order was proposed. The SI achieved the following TF parameters are represented in Table 3, is possible notice the result obtained from experiment, in this experiment is shown: the order of the System, the estimated values of each parameter depending on the order of the System, the fit to estimation data (FIT) and the final prediction error (FPE) for an estimated model. Analytically, the order of the System was calculated, based on the fifth-order system, when substituting numerical parameters, the order was reduced to 4 . Experiment uses a complete signal with a sampling of $0.1 \mathrm{~ms}$, simulation time of 60 seconds, disturbance of 0.2 and $\Delta_{r e f}$ is 0 . It can be concluded that for experiment, case 1 (fifth-order), had the best performance in terms of FIT and FPE.

Table 3. Model parameter comparation

\begin{tabular}{llllll}
\hline \multicolumn{5}{c}{} & \multicolumn{5}{c}{ Experiment 1} & Model \\
\hline Order & 5 & 4 & 3 & 2 & - \\
$\alpha_{4}$ & $-6.504 \times 10^{7}$ & - & - & - & - \\
$\alpha_{3}$ & $-11.44 \times 10^{12}$ & -0.02864 & - & - & - \\
$\alpha_{2}$ & $-2.288 \times 10^{16}$ & -572.94 & $9.831 \times 10^{5}$ & - & 53312 \\
$\alpha_{1}$ & $-5.557 \times 10^{15}$ & -139.1 & $-1.551 \times 10^{7}$ & -44.71 & 12950 \\
$\alpha_{0}$ & $-1.287 \times 10^{14}$ & -3.222 & $-1.655 \times 10^{6}$ & -4.424 & 300 \\
$\beta_{5}$ & 1 & - & - & - & - \\
$\beta_{4}$ & $3.995 \times 10^{13}$ & 1 & - & - & 1862 \\
$\beta_{3}$ & $4.859 \times 10^{14}$ & 12.16 & 1 & - & 22645 \\
$\beta_{2}$ & $8.767 \times 10^{14}$ & 21.94 & $3.139 \times 10^{5}$ & 1 & 40857 \\
$\beta_{1}$ & $1.305 \times 10^{14}$ & 3.265 & $5.188 \times 10^{5}$ & 1.458 & 6080 \\
$\beta_{0}$ & $2.14 \times 10^{12}$ & 0.05371 & $3.06 \times 10^{4}$ & 0.08147 & 100 \\
FIT & $100 \%$ & $100 \%$ & $92.59 \%$ & $90.06 \%$ & - \\
FPE & $7.878 \times 10^{-17}$ & $1.491 \times 10^{21}$ & $5.523 \times 10^{-6}$ & $9.92925 \times 10^{-6}$ & - \\
\hline
\end{tabular}

\subsection{Results and discussion}

In the structure that was implemented in this investigation, the parameter estimation technique used employs the use of different algorithms, here N4SID and GPMF were applied, the process performance was evaluated in an experiment. The results showed that the process is very precise when considering the order of the system obtained analytically. From the results obtained, it can be concluded that in order to identify the parameters of a model, it is appropriate to have a complete signal with a large database. The order of the proposed system is important, it can be concluded that the results of the experiment in terms of FIT and FPE, the best results were obtained with systems of fifth and fourth-order. For the estimation of the parameters, the performance of the method is exceptional, the N4SID and GPMF algorithms have had very similar results.

As can be seen from (7), only a fourth order TF is used to represent the complete system, mathematical operations were used to reduce to a minimum expression. As shown in the comparison of the model parameters in Table 3, the best prediction was presented in the order 4 and 5, it can be seen in the FIT to the simulation data and the FPE. It is possible to notice the result obtained from Figures 1 to 7 , in these experiments the prediction error is shown, which is minimum for cases 1 and 2.

\section{CONCLUSIONS}

A 5th order system was found analytically. When replacing the real data of the system within the equations, a 4th order system was obtained. Using the SI technique, fifth and fourth-order systems were 
obtained that comply $100 \%$ with the approach to the original signal, this means that the input-output response is the same for these cases. The sampling time was very important; they were carried out with $0.01,0.001$ and finally 0.0001 , which was used for having better results.

\section{ACKNOWLEDGEMENTS}

José Angel Barrios is grateful to CONACYT-Mexico for providing a Postdoctoral research fellowship and Loughborough University, UK, for the support provided during the research stay.

\section{REFERENCES}

[1] P. Pourbeik and J. Feltes, Dynamic Models for Turbine-Governors in Power System Studies, IEEE, 2013.

[2] A. Khodabakhshian and M. Edrisi, "A new robust PID load frequency controller," Control Eng. Pract., vol. 16, no. 9, pp. 1069-1080, 2008, doi: 10.1016/j.conengprac.2007.12.003.

[3] Jiang Chang, Zhi-Huai Xiao and Shu-Qing Wang, "Neural network model predict control for the hydroturbine generator set," Proceedings of the 2003 International Conference on Machine Learning and Cybernetics (IEEE Cat. No.03EX693), 2003, pp. 540-543 Vol.1, doi: 10.1109/ICMLC.2003.1264536.

[4] M. Djukanovic, M. Novicevic, D. Dobrijevic, B. Babic, D. J. Sobajic and Yoh-Han Pao, "Neural-net based coordinated stabilizing control for the exciter and governor loops of low head hydropower plants," in IEEE Transactions on Energy Conversion, vol. 10, no. 4, pp. 760-767, Dec. 1995, doi: 10.1109/60.475850.

[5] S. B. Crary and J. B. McClure, "Supplementary Control of Prime-Mover Speed Governors," Trans. Am. Inst. Electr. Eng., vol. 61, no. 4, pp. 209-214, doi: 10.1109/T-AIEE.1942.5058514.

[6] F. Gonzalez-Longatt, F. Sanchez and R. Leelaruji, "Unveiling the Character of the Frequency in Power Systems," 2019 IEEE PES GTD Grand International Conference and Exposition Asia (GTD Asia), 2019, pp. 5762, doi: 10.1109/GTDAsia.2019.8715972.

[7] F. Gonzalez-Longatt, J. Rueda, and E. Vazquez, "Effect of Fast Acting Power Controller of Battery Energy Storage Systems in the Under-frequency Load Shedding Scheme," International Conference on Innovative Smart Grid Technologies (ISGT Asia 2018), 2018.

[8] H. B. Ruud and S. B. Farnham, "A New Automatic Load Control for Turbine Generators," Trans. Am. Inst. Electr. Eng., vol. 68, no. 2, pp. 1337-1342, 1949, doi: 10.1109/T-AIEE.1949.5060096.

[9] D. Babunski and A. Tuneski, "Modelling and design of hydraulic turbine-Governor system," IFAC Proc. Vol., 2003, vol. 36, no. 7, pp. 263-267, doi: 10.1016/S1474-6670(17)35842-1.

[10] Y. Li, C. Peng, and Z. Yang, "Steam turbine governor modeling and parameters testing for power system simulation," Front. Energy Power Eng. China, vol. 3, pp. 198-203, 2009, doi: 10.1007/s11708-009-0004-2.

[11] M. L. Chan, R. D. Dunlop and F. Schweppe, "Dynamic Equivalents for Average System Frequency Behavior Following Major Distribances," in IEEE Transactions on Power Apparatus and Systems, vol. PAS-91, no. 4, pp. 1637-1642, July 1972, doi: 10.1109/TPAS.1972.293340.

[12] Y. Xie, H. Zhang, C. Li, and H. Sun, "Development approach of a programmable and open software package for power system frequency response calculation," Protection and Control of Modern Power Systems, vol. 2, no. 18, 2017, doi: 10.1186/s41601-017-0045-1.

[13] L. Ljung, "Perspectives on system identification," in Annual Reviews in Control, vol. 34, no. 1, pp. 1-12, 2010, doi: 10.1016/j.arcontrol.2009.12.001.

[14] R. Umrao and D. K. Chaturvedi, "Load frequency control using polar fuzzy controller," TENCON 2010 - 2010 IEEE Region 10 Conference, 2010, pp. 557-562, doi: 10.1109/TENCON.2010.5686740.

[15] H. Bevrani, "Robust Power System Frequency Control," in Power Electronics and Power Systems, USA: Springer, 2009.

[16] L. Ljung, System Identification: Theory for the User. Division of Simon and Schuster One Lake Street Upper Saddle River, NJ, United States: Prentice-Hall, 1998.

[17] D. J. Bearup, N. D. Evans, and M. J. Chappell, "The input-output relationship approach to structural identifiability analysis," Computer Methods and Programs in Biomedicine, vol. 109, no. 2, pp. 171-181, 2013, doi: 10.1016/j.cmpb.2012.10.012.

[18] T. Soderstrom, "On model structure testing in system identification," Int. J. Control, vol. 26, no. 1, pp. 1-18, 1977, doi: 10.1080/00207177708922285

[19] N. K. Sinha and G. P. Rao, Identification of Continuous-Time Systems: Methodology and Computer Implementation. Springer Netherlands, 2012, doi: 10.1007/978-94-011-3558-0.

[20] H. Unbehauen and G. P. Rao, "A review of identification in continuous-time systems," Annu. Rev. Control, vol. 22, pp. 145-171, 1998, doi: 10.1016/S1367-5788(98)00015-7.

[21] D. C. Saha, V. N. Bapat, and B. K. Roy, "The Poisson moment functional technique - Some new results," in Identification of Continuous-Time Systems: Methodology and Computer Implementation, N. K. Sinha and G. P. Rao, Eds. Dordrecht: Springer Netherlands, 1991, pp. 327-361, doi: 10.1007/978-94-011-3558-0_11.

[22] P. Van Overschee and B. De Moor, "N4SID: Subspace algorithms for the identification of combined deterministicstochastic systems," Automatica, vol. 30, no. 1, pp. 75-93, 1994, doi: 10.1016/0005-1098(94)90230-5.

[23] B. De Moor and P. Van Overschee, "Numerical Algorithms for Subspace State Space System Identification," in Trends in Control, pp. 385-422, 1995, doi: 10.1007/978-1-4471-3061-1_12. 
[24] I. W. Jamaludin, N. A. Wahab, N. S. Khalid, S. Sahlan, Z. Ibrahim and M. F. Rahmat, "N4SID and MOESP subspace identification methods," 2013 IEEE 9th International Colloquium on Signal Processing and its Applications, 2013, pp. 140-145, doi: 10.1109/CSPA.2013.6530030.

[25] L. Ljung, “System Identification Toolbox, User's Guide," in Matlab R 2015, 3 Apple Hill Drive Natick, MA, USA: The MathWorks, 2015.

\section{BIOGRAPHIES OF AUTHORS}

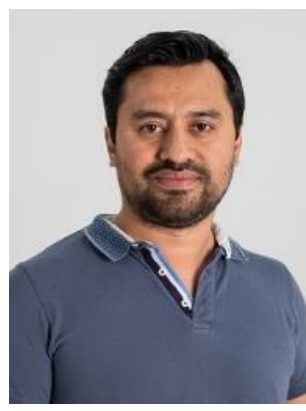

José Ángel Barrios Gómez received the title of Electromechanical Engineer by the Instituto Tecnologico de Tapachula, Mexico in 2004. He graduated from the Master of Science in Electrical Engineering in 2008 and finished the $\mathrm{PhD}$ degree in Electrical Engineering in 2016, respectively. Both degrees from the faculty of mechanical and electrical engineering (FIME) at the Universidad Autonoma de Nuevo Leon (UANL) in Mexico. Currently he is a part time lecture at the Polytechnic University of Apodaca and a part time lecture at the FIME in the UANL. Postdoctoral position in Loughborough University, UK. His research interests include modelling using intelligent systems and application of neural networks.

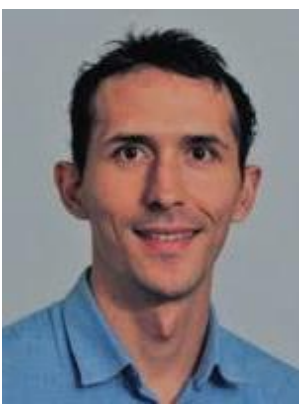

Francisco Sanchez Gorostiza received the B.Sc. degree in Electrical Engineering from Simon Bolivar University, Caracas, Venezuela, in 2011 and the Master's degree in Renewable Energy Technologies from Polytechnic University in Madrid, Spain, in 2013. He is currently pursuing a PhD. degree in Electrical Engineering at Loughborough University in the UK. His research is focused on the development of artificial intelligence techniques for power system analysis and energy management applications.

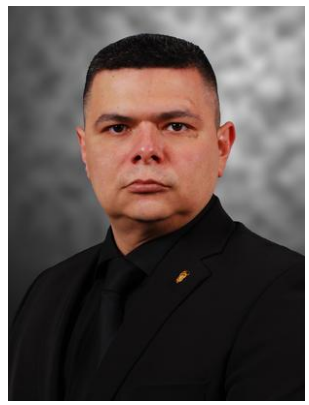

Francisco M. Gonzalez-Longatt is currently a full professor in electrical power engineering at Institutt for elektro, IT og kybernetikk, Universitetet i Sørøst-Norge, Norway. His research interest includes innovative (operation/control) schemes to optimize the performance of future energy systems. He has prolific research productivity including several industrial research projects and consultancy worldwide. Also, he is the author or editor of several books (Spanish and English), Associated editor in several journals with an impressive track record on scientific publications. Prof. Longatt is Vice-President of Venezuelan Wind Energy Association, a member of The Institution of Engineering and Technology - The IET (UK) and a member of International Council on Large Electric Systems - CIGRE. He received the professional recognition as FHEA - Fellow of the Higher Education Academy in January 2014

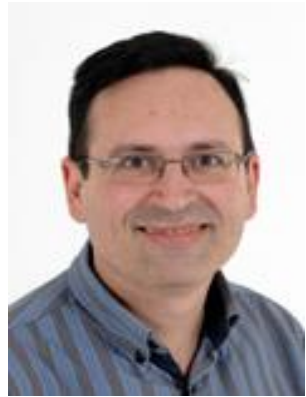

Gianfranco Claudio obtained a First-Class Degree in Physics from the University of Bari (Italy) in 1998 before joining the University of Surrey in 2000 where he obtained a $\mathrm{PhD}$ in Electronic Engineering in 2004. He is a Member of the Institute of Physics since 2004 and Chartered Physicist since 2009. He then accepted a Research Associate position at CREST within the Electronic Electrical and System Engineering School at Loughborough University working on developing highly efficient silicon solar cells investigating the antireflective properties of thin film dielectric grown by reactive sputtering. He also actively participated at the construction of the new PV laboratory at Holywell Park, Loughborough. 